Original papers

\title{
A compiled project and open-source code to generate web-based forest modelling simulators
}

\author{
Esteban Gómez-García ${ }^{\mathrm{a}}$, João C. Azevedo ${ }^{\mathrm{b}}$, Fernando Pérez-Rodríguez ${ }^{\mathrm{b}, *}$ \\ ${ }^{\text {a }}$ Centro de Investigación Forestal de Lourizán, Xunta de Galicia, Pontevedra, Spain

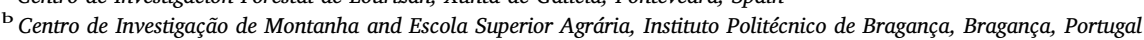

\section{A R T I C L E I N F O}

\section{Keywords:}

Forest simulator

ASP.Net

Cloud computing

Software as a service

Knowledge transfer

\begin{abstract}
A B S T R A C T
Sustainable forest management requires decision support systems to evaluate possible scenarios and anticipate the consequences of decisions. Forest modellers typically develop complex systems of equations to predict the behaviour of forests which makes the use of forest models difficult for end-users in general, affecting transfer of knowledge and technology. To overcome these difficulties and facilitate their practical use, models can be integrated into software to generate user-friendly forest simulators. In this paper we introduce and describe ForestMTIS, a cloud computing compiled and editable open-source project to generate forest simulators which was developed for statistical, non-spatial, deterministic, disaggregated, single species even-aged stand growth and yield models. We demonstrate the use of ForestMTIS based on the development of FlorNExT ${ }^{\circledR}$, its first practical application, based on a collaborative approach to make growth and yield modelling and sustainable forest management available to a large community of users in the Northeast of Portugal.
\end{abstract}

\section{Introduction}

Sustainable management of resources has been a widely studied topic in forest research (MacDicken et al., 2015). Forest management is a set of spatial/temporal decisions to achieve one or several goals under a sustainability framework (Borges et al., 2014). The management of resources demands anticipation of the consequences that decisions might have on the forest ecosystem (Hynynen et al., 2015). Decisionmakers need, therefore, based on the best available information, to evaluate the current condition of the forest and to predict the future short and /or long term state of the system based on simulations of possible scenarios (Ludwig, 1993).

Defining the state of the forest involves increasing information levels because more and more factors and actors require consideration (Lidskog and Löfmarck, 2016). Decision Support Systems (DSS) have become progressively useful in decision-making to design and implement proper sustainable forest resources management schemes (Gadow and Pukkala, 2008). Moreover, DSS are useful for researchers and students to better understand forest dynamics and how forests can be affected by human management (Kulakowski et al., 2017).

Forest growth and yield models developed for natural or planted single species even-aged stands can be a DSS or a subset in a more complex DSS. These forest models, and in general DSS, are usually comprised of a large number of equations and algorithms with the purpose of producing useful estimates. This complexity often makes it difficult for end-users to apply forest modelling in management or even research, inhibiting effective transfer of knowledge and technology. To facilitate the practical use of forest models, these can be integrated into software able to generate simulators (Lorek and Sonnenschein, 1999) with user-friendly application forms and automated processes for execution and display of results. In these forest simulators, models are fixed and the end-user can adapt them to his/her needs by setting inputs. Simulators are best suited to meet the needs of end-users who work with existing models (Larocque et al., 2015). The development of forest simulators has been increasing in the last decades. For example, various pieces of software are combined in several DSS tools described in the FORSYS Wiki (Packalen et al., 2013), in the ForestDSS web page (ForestDSS, 2016), the Capsis platform (Capsis, 2016) or in the Tools \& Applications webpage of the USDA Forest Service (2016). Most of these are desktop tools but hypertext technology developments in the late 20th century, such as ASP or PHP, opened the possibility to apply simulators in cloud computing. Briefly, hypertext technology allows embedding text scripts that can run on the user's computer, enabling interaction with the server (Adebukola and Kazeem, 2014). Cloud computing presents many advantages over desktop computing, such as adaptability to different platforms, independence of operating system, and easy ways of improving and updating existing versions (Dillon et al., 2010). Nevertheless, some disadvantages can be pointed out such

\footnotetext{
* Corresponding author at: Escola Superior Agrária, Instituto Politécnico de Bragança, Campus de Santa Apolónia, $5300-253$ Bragança, Portugal.

E-mail addresses: esteban.gomez.garcia@xunta.es (E. Gómez-García), jazevedo@ipb.pt (J.C. Azevedo), fernando.perez@ipb.pt (F. Pérez-Rodríguez).
} 


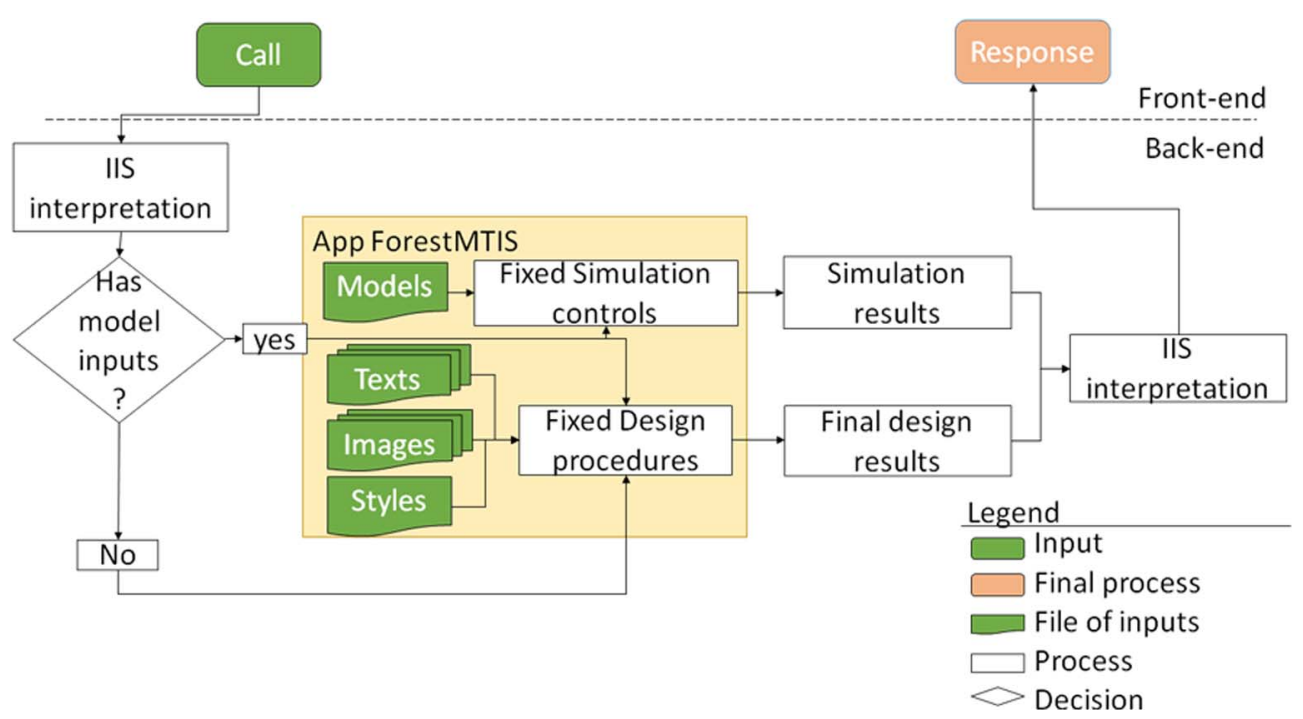

Fig. 1. Flux diagram of the generic ForestMTIS project.

as the requirement for periodic maintenance and computational capacity limitations, depending on the server capacity (Nwobodo, 2016). EucaTool $^{\circledast}$ (Rojo-Alboreca et al., 2015) and WEB-Globulus (Palma, 2016) are good examples of cloud computing applications in the Iberian Peninsula.

Forest modellers are usually not programmers and costs of developing software or license issues may prevent them to develop simulators. However, the increasing availability of free or open-source software facilitates integration of models into modelling and simulation platforms. According to Larocque et al. (2015), modellers and end-users must spend more time on model development or analysis of simulation results than on programming. Nevertheless, there is a gap between modellers and end-users which is recognized in forestry and in many other fields (Folke et al., 2005). Forest modellers should make all efforts for an effective knowledge and technology exchange and transfer, especially when it can be applied in improving sustainable management and decision making in natural resources (Vacchiano et al., 2012).

In this context we developed ForestMTIS (Forest Models, Texts, Images, and Style), a compiled and editable open-source project to generate simulators. The objectives were (i) to assist forest modellers in the transfer of stand models to end-users, (ii) to provide end-users with an user-friendly simulator interface to support sustainable forest management, and (iii) to publish the code to open future improvements by programmers.

\section{Materials and methods}

\subsection{ForestMTIS project, abstraction and generalization}

ForestMTIS was created as a generic forest simulator open-source project that can be synthetized in simple procedures to facilitate interactions of end-users with forest growth and yield models. Briefly, this synthesis can be hierarchized in: (i) input forms, (ii) transformation and calculation procedures, and (iii) output forms. In the particular case of web development, the input and output forms are part of the front-end (Lara et al., 2013). The front-end of a website is where users interact with the webpage, in the case of ForestMTIS where data is inputted by users in controls like text boxes and output data is displayed in graphics or tables and where it can be downloaded from. The transformation and calculation procedures is the back-end of the development that often runs in a server. Here, controls or procedures call the models inputting data and producing output results of the simulations. The interaction between the front-end and the back-end is based on request and responses transferred by Hypertext Transfer Protocol (HTTP).
These kinds of developments follow the same functioning of desktop tools in the sense that the application is executed by the set of files that comprise the application but, as web developments, they differ from these since the application runs in a server using an interpreter like Apache or IIS to connect front and back end. These interpreters deploy, manage and run the web applications, establishing the interaction with the client using remote calls to public IP addresses or URLs (Talwar et al., 2005). This philosophy of software development is known as Software as a Service (SaaS) (Ma, 2007) because the owner of the application offers the service without the possibility of modifying the architecture of the development and maintaining the security and integrity of the procedures. This kind of cloud applications do not, therefore, require specific installation and can be freely accessed from any internet-connected device (desktop or laptop computer, mobile phone, smartphone, tablet, etc.).

The ForestMTIS project was developed in ASP.Net using MVC 4.5 technology. It is hosted in Open Source Repository (https://sourceforge.net/projects/forestmtis/) in two forms: (i) the editable project (ForestMTIS_Project folder) and (ii) the compiled project (ForestMTIS_Compiled folder). The editable project requires programming knowledge to be handled because it contains all the application procedures code and it requires an Integrated Development Environment (IDE) of C\#, such as Visual Studio, to be opened. By providing the full code we intend to keep open the possibility for potential users to modify the architecture of the development, reuse the code or interpret and translate it in other languages. The compiled project requires less technical knowledge to be used. The compilation includes fixes and editable files (Fig. 1). The fixed files resulted of the compiled C\# project that are not allowed to been modified to maintain the stability of the procedures (Fixed Simulation controls and Fixed Design procedures). Editable files are organized according to the following sections: (i) Models, containing the developed models, (ii) Texts, a set of files containing all texts of the application, (iii) Images, used to define the front-end appearance, and (iv) Style, or Cascading Style Sheets (CSS), that contains the formats of each of the elements in the tool (i.e., colours, font type and size, width and height of panels, etc.). The fixed files are dynamic-link libraries ( $d l l)$ run by the deployment application IIS. These files include all procedures required to call and use Models, Texts, Images and Styles files in the project.

\subsection{Forest modelling requirement}

ForestMTIS was developed to generate simulators which work with disaggregated statistical non-spatial deterministic even-aged stand 
models (Weiskittel et al., 2011), based on the state-space approach (García, 1994). The stand condition at any point in time is based on four state variables: stand age $(t)$, dominant height $\left(H_{0}\right)$, tree density $(N)$ and basal area $(G)$. The model required first the development of a dynamic sub-model which consists in three transition functions to predict the evolution of the state variables $H_{0}, N$ and $G$. However, in order to provide more flexibility to forest modellers, ForestMTIS offers two other possibilities to predict $N$, namely a maximum $N$ equation and the exclusion of mortality. In addition, it includes a $G$ initialization function which should only be used to provide an initial value at a given $t$, and not to project $G$ over time. ForestMTIS stand output variables are total volume and biomass. Moreover, carbon stock is estimated by a carbonbiomass relationship.

In a second step observed or estimated stand state variables at a particular time are disaggregated mathematically in order to estimate tree level variables (Weiskittel et al., 2011). The two-parameter Weibull function was selected to model tree diameter distributions. The function parameters are obtained by the parameter recovery method through moments using the expressions of Cao et al. (1982). The use of a generalized height-diameter relationship allows estimating the height of the average tree in each diameter class. In the development of generalized height-diameter relationships modellers use available stand variables but dominant diameter $\left(d_{0}\right)$ is also often used. If necessary, ForestMTIS takes $d_{0}$ directly from the diameter distribution estimation. Finally, an individual-tree total volume equation used in the "thinning simulator" provided in ForestMTIS is required. The end-user can define thinning schemes by selecting the type of thinning (from below or systematic) and the number or percentage of trees to extract. The volume extracted in each thinning is computed applying the individualtree volume equation over the number of target trees whose diameters and heights were estimated in the disaggregation process.

Therefore, implementation of ForestMTIS requires nine to ten (considering mortality or not) equations (Table 1). Similar models and detailed descriptions of model development are provided in DiéguezAranda et al. (2006), Castedo Dorado et al. (2007) or Gómez-García et al. (2015).

\subsection{Customizing ForestMTIS}

The compiled project is the application ready to run, including direct connections among the files that comprise it (Models, Texts, Images and Styles), meaning that if one file is modified the tool automatically updates the front-end when running on the cloud. Texts, Images and Styles can be modified editing files directly with common text editors or replacing images maintaining in all the cases the name of the files

Table 1

Equations required for the implementation of ForestMTIS.

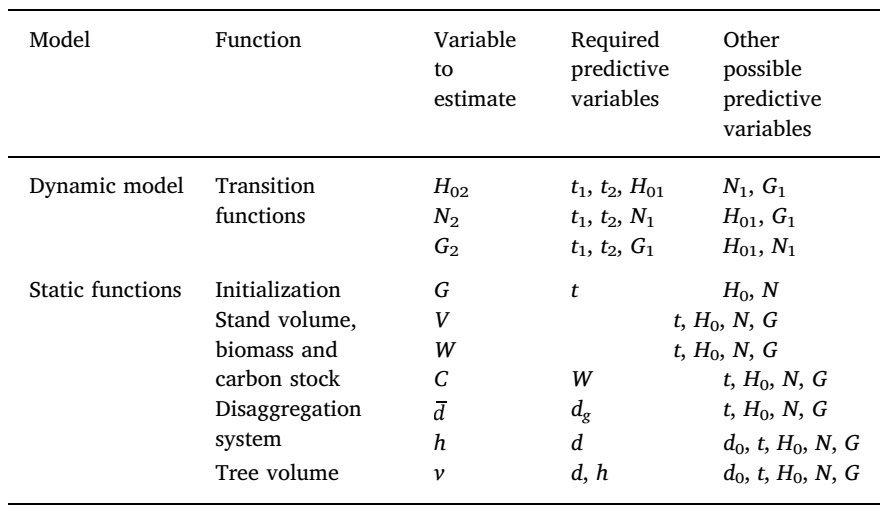

Note: $t=$ stand age; $H_{0}=$ dominant height; $N=$ number of trees per hectare; $G=$ stand basal area; $V=$ total stand volume; $W=$ total stand biomass; $C=$ stand carbon stocks; $\bar{d}=$ mean diameter; $d_{g}=$ quadratic mean diameter; $d_{0}=$ dominant diameter; $d=$ breast height tree diameter; $h=$ total tree height; $v=$ individual-tree total volume. previously used, and maintaining the order of the sentences in the case of Texts (Fig. 2). In the case of Models, however, modifications involve more steps. These changes are implemented in a dll file which is structured and documented to be editable (see example of code in Code. 1). The library contains two types of information: (i) metadata and setup of equations (i.e., the $\mathrm{max} / \mathrm{min}$ range of inputs and the references to the model), and (ii) the procedures or scripts with the model equations. To make changes in equations possible, the project C\# code is provided (DinamicModelLibrary_Project folder) at https://sourceforge.net/projects/forestmtis) allowing access to it with IDEs (Integrated Development Environment) such as Microsoft Visual Studio. After modification, the dll must be compiled and equations will automatically be implemented in ForestMTIS overwriting the previous version. The library was prepared to hold information to support three different species or subsets.

\section{Results}

\subsection{FlorNExT ${ }^{\circledast}$, an application of ForestMTIS}

FlorNExT ${ }^{\circledast}$ (Pérez-Rodríguez et al., 2016) is the first practical fully developed application of ForestMTIS. The development process was based on an open and collaborative feedback process involving modellers, programmers and end-users to establish and improve FlorNExT ${ }^{\oplus}$ and with it ForestMTIS. Briefly, FlorNExT ${ }^{\circledR}$ combines models to predict growth and yield of even-aged stands of Pinus pinaster Ait. and Quercus pyrenaica Willd. in Northeastern Portugal. The application is available in three languages (English, Portuguese and Spanish). It is hosted by a server owned by the Polytechnic Institute of Bragança, Portugal, and it is accessible from the address http://flornext.esa.ipb.pt/.

The collaborative framework established to develop FlorNExT ${ }^{\circledast}$ included workshops and direct interviews. Feed-back resulted in changing Texts, Images and Style following simplicity and user-friendly principles. Moreover, ForestMTIS was improving in this process by implementing more options and text to display more information to end-users. For example, in the "Home page" we implemented a link to the user's guide, in the "Growth simulator" and "Thinning simulator" sections we created help text to describe input variables to overcome possible lack of technical forest knowledge of end-users, and in the output we have improved the presentation of results to better explain the sequence and details of this section.

\subsection{Software availability}

The ForestMTIS is provided completely in Open Source Repository (https://sourceforge.net/projects/forestmtis/) as an editing project and as a compiled project. Developer: Fernando Pérez-Rodríguez (fernando.perez@ipb.pt). Year of first available: 2017. Software requires: Visual Studio. Program language: C\#, HTML, JavaScript and XML. Program size: Project (21.4 MB) and Compiled (12.9 MB). Moreover the application example FlorNExT ${ }^{\circledR}$ (Pérez-Rodríguez et al., 2016) is available in http://flornext.esa.ipb.pt where the user guide is also available in English, Portuguese and Spanish.

\section{Discussion}

In the last decades forest modelling has undergone a great development and the use of forest simulators has been increasing. Forest modellers should take the potential end-users into consideration (Jin et al., 2016) but the effective use of models and simulators by end-users has been commonly considered as a secondary issue. Even active transfer policies aiming to bringing together researchers and other actors do not guarantee that the actual knowledge acquired generates innovation (Chapman, 2013). Therefore, the effective transfer of simulators to end-users, the training to apply these tools and the evaluation of their effective use is still an open path in forestry. FlorNExT ${ }^{\circledR}$, 


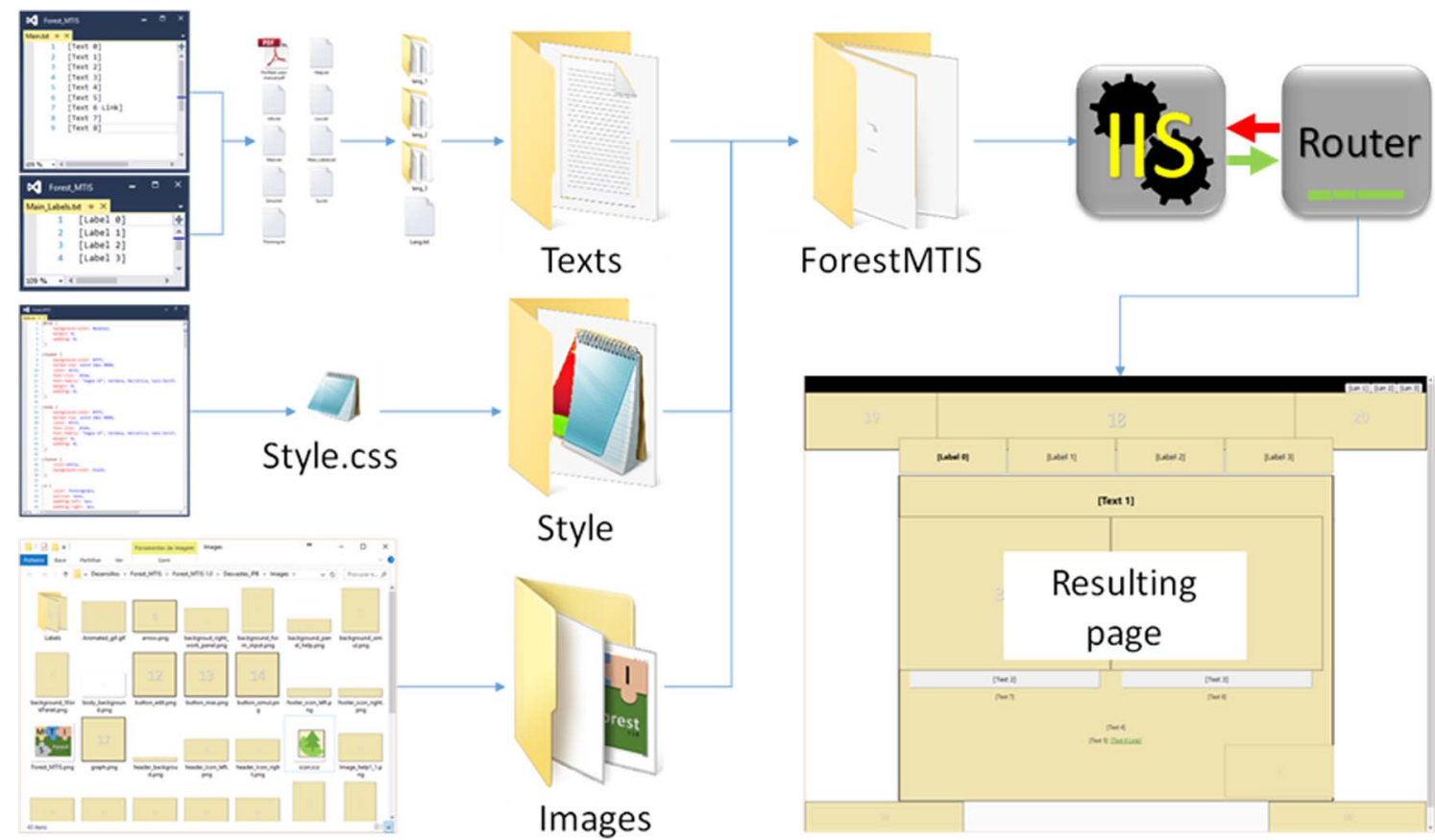

Fig. 2. Hierarchical scheme of files (Texts, Styles and Images) that can be modified in ForestMTIS.

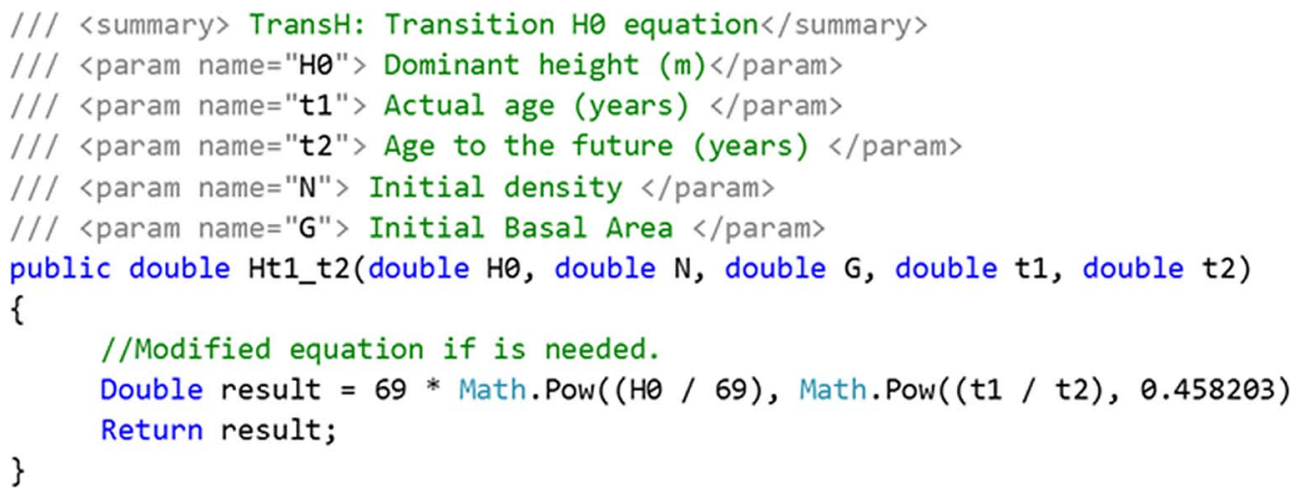

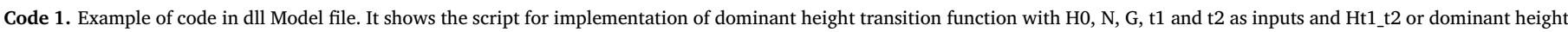
in $\mathrm{t} 2$ as output.

the first application of ForestMTIS, is a compilation of models from different modellers and a direct link with the end-users, contributing to direct transferring of research results and learning regarding sustainable forest management.

Van Voorn et al. (2016) pointed out three criteria for end-users to have interest in models which can also be extended to simulators: (i) credibility, i.e., if the model is considered an acceptable approximation of the modelled system, (ii) salience, i.e., if it can answer the questions that are raised, and (iii) legitimacy, i.e., when it represents fairly the views, values and concerns of involved stakeholders. In addition, modellers should be aware of four points (van Voorn et al., 2016): (a) the three criteria above cannot be considered equal but should be balanced, (b) the criteria can be counteracting, (c) the perception of credibility varies among modellers and end-users, and (d) the perception of the three criteria seem to be dynamic and may be path-dependent. Therefore, models developed without feed-back or even involvement of end-users can be salient but not credible or legitimate. The collaborative framework created for FlorNExT $^{\circledR}$ was carried out to provide more credibility and legitimacy and in order to improve the effective use of this simulator.

In relation to credibility, modellers should highlight to end-users that all models have implicit some uncertainty. Regarding the projection interval, Mäkinen et al. (2008) suggested the use of stand level models for long-term projections ( $>20$ years) and individual-tree models for short-term projections $(<10$ years). This is because prediction errors tend to accumulate, particularly in more complex models (Kangas, 1997). The structure of forest models used in ForestMTIS involves a stand level model to estimate growth but a disaggregation system predicts tree level variables. Therefore, predictions carried out for time intervals over 15-20 years should be considered with caution (Gómez-García et al., 2015).

On the other hand, Robinson and Monserud (2003) assessed seven individual-tree simulators for the Pacific Northwest in the US, and considered that adaptability is probably the most important aspect explaining the use of simulators. These authors introduced criteria to evaluate the adaptability of simulators where the four most important were portability, extendibility, open-source code, and adequate documentation. ForestMTIS complies with these four criteria in that simulators are based in simple principles, they are thoroughly documented, and uses open-source code.

In order to improve transfer and effective use, ForestMTIS generate web-based simulators. A simulator created within this project does not require extensive inputs and is less computing demanding which is particularly relevant in web-based tools. The internet has become 
widely used to access knowledge and information by all categories of stakeholders, including end-users of diverse interests and technical backgrounds (McKinley et al., 2012). A common simple and easy to use and operate language is needed in the forest sector, and while interactive web-based tools are emerging and expanding, internet remains underutilized and has not met its considerable potential (Ugolini et al., 2015).

\section{Conclusions}

ForestMTIS is an open-source project (compiled and editable) to create simulators as web pages. It enables the forest modellers to make available developed forest growth and yield models to end-users by generating a simulator with a user-friendly interface and automating the execution. It was developed to specific forest growth and yield models (statistical, non-spatial, deterministic, disaggregated, single species even-aged stand models) because, of their simplicity and usability, they can be more widely used. Simulators generated in ForestMTIS can predict the dynamics of the stand variables such as dominant height, stand basal area and number of trees, and to estimate stand volume, biomass and carbon stocks. The disaggregated system allows estimating individual-tree variables such as number of trees in each diameter class and the individual-tree volume. A thinning simulator is also possible to develop based on the tool.

Forest modellers should include the transfer of developed models to end-users as a priority of their researcher. Therefore, the publication of models and results in scientific publications should be complemented with the generation of a simulator with a common language, ease of access and friendly user. An effective advertising of the existence of this specific software and training are also fundamental tasks.

\section{Acknowledgements}

This work was funded by the EU-FP7 SIMWOOD project (Sustainable Innovative Mobilisation of Wood) under Grant Agreement No. 613762, the Spanish Government through INIA; and the Galician Regional Government (Xunta de Galicia) through INGACAL. The authors acknowledge also the support provided by the Mountain Research Centre and the School of Agriculture of the Polytechnic Institute of Bragança, Portugal, during a research stay of the first author.

\section{References}

Adebukola, O.M., Kazeem, O.B., 2014. Performance comparison of dynamic web scripting language: a case study of PHP and ASP.NET. Int. J. Sci. Eng. Res. 5 (7), 78-89.

Borges, J.G., Diaz-Balteiro, L., McDill, M.E., Rodriguez, L.C.E., 2014. The Management of Industrial Forest Plantations: Theoretical Foundations and Applications. Springer, London.

Cao, Q.V., Burkhart, H.E., Lemin, R.C., 1982. Diameter Distributions and Yields of Thinned Loblolly Pine Plantations. School of Forestry and Wildlife Resources. VPI and SU, Publication (No. FSW-1-82).

Castedo Dorado, F., Diéguez-Aranda, U., Álvarez González, J.G., 2007. A growth model for Pinus radiata D. Don stands in north-western Spain. Ann. For. Sci. 64, 453-465.

Chapman, K., 2013. Complexity \& Creative Capacity: Reformulating the Problem of Knowledge Transfer in Environmental Management. Ph.D. Thesis. Edith Cowan University, Australia.

Capsis, 2016. Capsis: Computer-Aided Projection for Strategies in Silviculture. Capsis projects. < http://capsis.cirad.fr/capsis/models > . (accessed 23.11.2016).

Diéguez-Aranda, U., Castedo-Dorado, F., Álvarez-González, J.G., Rodríguez-Soalleiro, R., 2006. Dynamic growth model for Scots pine (Pinus sylvestris L.) plantations in Galicia (north-western Spain). Ecol. Modell. 191, 225-242.

Dillon, T., Wu, C., Chang, E., 2010. Cloud computing: issues and challenges. In: 2010 24th IEEE International Conference on Advanced Information Networking and Applications, pp. 27-33.
Folke, C., Hahn, T., Olsson, P., Norberg, J., 2005. Adaptive governance of social-ecological systems. Ann. Rev. Environ. Resour. 30, 441-474.

ForestDSS, 2016. ForestDSS wiki. < http://www.forestdss.org/ > (accessed 24.10.16)

Gadow, K.v., Pukkala, T., 2008. Designing Green Landscapes. Managing Forest Ecosystems, vol. 15 Springer, Verlag, Dordrecht, Holland.

García, O., 1994. The state-space approach in growth modelling. Can. J. For. Res. 24, 1894-1903.

Gómez-García, E., Crecente-Campo, F., Barrio-Anta, M., Diéguez-Aranda, U., 2015. A disaggregated dynamic model for predicting volume, biomass and carbon stocks in even-aged pedunculate oak stands in Galicia (NW Spain). Eur. J. Forest Res. 134, 569-583.

Hynynen, J., Salminen, H., Ahtikoski, A., Huuskonen, S., Ojansuu, S., Siipilehto, J., Lehtonen, M., Eerikäinen, K., 2015. Long-term impacts of forest management on biomass supply and forest resource development: a scenario analysis for Finland. Eur. J. Forest Res. 134 (3), 415-431.

Jin, W., Hong, S.He, Thompson III, F.R., 2016. Are more complex physiological models of forest ecosystems better choices for plot and regional predictions? Environ. Modell. Softw. 75, 1-14.

Kangas, A., 1997. On the prediction bias and variance in long-term growth projections. For. Ecol. Manage. 96, 207-216.

Kulakowski, D., Seidl, R., Holeksa, J., Kuuluvainen, T., Nagel, T.A., Panayotov, M., Svoboda, M., Thorn, S., Vacchiano, G., Whitloc, C., Wohlgemuth, T., Bebi, P., 2017. A walk on the wild side: disturbance dynamics and the conservation and management of European mountain forest ecosystems. For. Ecol. Manage. 338, 120-131.

Lara, J.A., Lizcano, D., Martínez, M.A., Pazos, J., 2013. Developing front-end Web 2.0 technologies to access services, content and things in the future Internet. Future Gener. Comp. Sy. 29 (5), 1184-1195.

Larocque, G.R., Bhatti, J., Arsenault, A., 2015. Integrated modelling software platform development for effective use of ecosystem models. Ecol. Modell. 306, 318-325.

Lidskog, R., Löfmarck, E., 2016. Fostering a flexible forest: challenges and strategies in the advisory practice of a deregulated forest management system. For. Policy Econ. $62,177-183$.

Lorek, H., Sonnenschein, M., 1999. Modelling and simulation software to support individual-based ecological modelling. Ecol. Modell. 115, 199-216.

Ludwig, D., 1993. Forest management strategies that account for short-term and longterm consequences. Can. J. For. Res. 23 (4), 563-572.

Ma, D., 2007. The Business Model of "Software-As-A-Service". In: IEEE International Conference on Services Computing (SCC 2007). Salt Lake City, USA.

MacDicken, K.G., Sola, P., Hall, J.E., Sabogal, C., Tadoum, M., de Wasseige, C., 2015. Global progress toward sustainable forest management. For. Ecol. Manage. 352, 47-56.

Mäkinen, A., Kangas, A., Kalliovirta, J., Rasinmäki, J., Välimäki, E., 2008. Comparison of treewise and standwise forest simulators by means of quantile regression. For. Ecol. Manage. 255, 2709-2717.

McKinley, D.C., Briggs, R.D., Bartuska, A.M., 2012. When peer-reviewed publications are not enough! Delivering science for natural resource management. For. Policy Econ. 21, 1-11.

Nwobodo, I., 2016. Cloud computing: models, services, utility, advantages, security issues, and prototype. In: Zeng, Q.A. (Ed.), Wireless Communications, Networking and Applications. Springer, India, pp. 1207-1222.

Packalen, T., Marques, A.F., Rasinmäki, J., Rosset, C., Mounir, F., Rodriguez, L.C.E., Nobre, S.R., 2013. Review. A brief overview of forest management decision support systems (FMDSS) listed in the FORSYS wiki. Forest Sys. 22 (2), 263-269.

Palma, J.H.N., 2016. Web Globulus 3.0. < http://home.isa.utl.pt/ joaopalma/modelos/ webglobulus/ > (accessed 22.10.2016).

Pérez-Rodríguez, F., Nunes, L., Sil, A., Azevedo, J.C., 2016. FlorNExT ${ }^{\oplus}$, a cloud computing application to estimate growth and yield of maritime pine (Pinus pinaster Ait.) stands in Northeastern Portugal. Forest Sys. 25 (2) eRC08, 6 pages.

Robinson, A.P., Monserud, R.A., 2003. Criteria for comparing the adaptability of forest growth models. For. Ecol. Manage. 172 (1), 53-67.

Rojo-Alboreca, A., García-Villabrille, J.D., Pérez-Rodríguez, F., 2015. EucaToolº a cloud computing application for estimating the growth and production of Eucalyptus globulus Labill. plantations in Galicia (NW Spain). Forest Sys. 24 (3), 1 (eRC06, 4 pages).

Talwar, V., Milojicic, D., Wu, Q., Pu, C., Yan, W., Jung, G., 2005. Approaches for service deployment. IEEE Internet Comput. 9 (2), 70-80.

Ugolini, F., Massetti, L., Sanesi, G., Pearlmutter, D., 2015. Knowledge transfer between stakeholders in the field of urban forestry and green infrastructure: results of a European survey. Land Use Policy 49, 365-381.

USDA Forest Service, 2016. Northern Research Station. Tools \& Applications. < http:// www.nrs.fs.fed.us/tools/software/ > (accessed 21.10.2016).

Vacchiano, G., Magnani, F., Collalti, A., 2012. Modeling Italian forests: state of the art and future challenges. iForest 5 (3), 113-120.

van Voorn, G.A.K., Verburg, R.W., Kunseler, E.-M., Vader, J., Janssen, P.H.M., 2016. A checklist for model credibility, salience, and legitimacy to improve information transfer in environmental policy assessments. Environ. Modell. Softw. 83, 224-236.

Weiskittel, A.R., Hann, D.W., Kershaw Jr, J.A., Vanclay, J.K., 2011. Forest Growth and Yield Modeling. Wiley-Blackwell, Oxford, UK. 